\title{
Hepatoprotective activity of Moringa oleifera against cadmium toxicity in rats
}

\author{
Reetu Toppo, Birendra Kumar Roy, Ravuri Halley Gora, Sushma Lalita Baxla and Prabhat Kumar \\ Department of Veterinary Pharmacology \& Toxicology, College of Veterinary Science \& A. H., Birsa Agricultural University, \\ Ranchi - 834 006, Jharkhand, India. \\ Corresponding author: Ravuri Halley Gora, e-mail: halleygora@gmail.com, RT: drreetuoraon@gmail.com, \\ BKR: roybk2001@yahoo.co.in, SLB: sushmalbaxla@gmail.com,PK: guddunalanda@gmail.com \\ Received: 04-12-2014, Revised: 23-03-2015, Accepted: 28-03-2015, Published online: 24-04-2015
}

doi: 10.14202/vetworld.2015.537-540. How to cite this article: Toppo R, Roy BK, Gora RH, Baxla SL, Kumar P (2015) Hepatoprotective activity of Moringa oleifera against cadmium toxicity in rats, Veterinary World 8(4); 537-540.

\begin{abstract}
Aim: The present investigation has been conducted to evaluate the hepatoprotective activity of Moringa oleifera against cadmium-induced toxicity in rats.

Materials and Methods: For this study, 18 Wistar albino rats were taken. Control group, Group I rats were given cadmium chloride@200 ppm per kg and Group II rats were treated with M. oleifera extract @ 500 mg/kg along with cadmium chloride@200 ppm per kg (daily oral for 28 days). On 29 $9^{\text {th }}$ day, animals were slaughtered and various parameters were determined. Serum biomarkers, oxidative stress parameters, histomorphological examination were carried out with estimation of cadmium concentration in liver tissues.

Results: Oral administration of cadmium chloride@ 200 ppm $/ \mathrm{kg}$ for 28 days resulted in a significant increase in aspartate aminotransferase (AST), alanine transaminase (ALT), alkaline phosphatase (ALP), significant $(\mathrm{p} \leq 0.01)$ increase of lipid peroxidation (LPO) and decrease in superoxide dismutase (SOD), and increase in cadmium accumulation in liver. Treatment with $M$. oleifera@ $500 \mathrm{mg} / \mathrm{kg}$ significantly $(\mathrm{p}<0.01)$ decreased the elevated ALP, AST, ALT, LPO levels and increase in SOD levels, and as compared to cadmium chloride treated group. However, there was no significant difference in cadmium concentration in liver when compared with cadmium chloride treated group.
\end{abstract}

Conclusion: The study conclude that supplementation of $M$. oleifera $(500 \mathrm{mg} / \mathrm{kg})$, daily oral for 28 days has shown protection against cadmium-induced hepatotoxicity.

Keywords: cadmium, Moringa oleifera, rats, serum bio-markers, toxicity.

\section{Introduction}

The exposure to the toxic metals has become an increasingly recognized source of illness worldwide $[1,2]$. Cadmium is a well-known heavy metal present in the environment and causes serious environmental and occupational hazard to human $[3,4]$. Cadmium induces lipid peroxidation by stimulating the production of superoxide anions and inhibits antioxidants such as glutathione peroxidase and superoxide dismutase and cause accumulation of free radicals that damage the cells and produce chronic disease [5]. Medicinal plants are the backbone of traditional medicine, which means more than 3.3 billion people in the less developed countries, utilizes medicinal plants on a regular basis [6]. Moringa oleifera is referred as "Miracle tree" in tropics and subtropics with a wide range of the beneficial effect, which was predicted in Indian system of medicine (Ayurveda and Unani) [7]. The plant is reported to possess antitumor, antipyretic, anticonvulsant, anti-inflammatory [8], antiulcer, antispasmodic, antidiabetic, diuretic, antihypertensive, antioxidant antifungal, antibacterial $[9,10]$, antiretroviral, antisepticemic, antidiarrheal, and can be used to

Copyright: The authors. This article is an open access article licensed under the terms of the Creative Commons Attributin License (http:// creative commons.org/licenses/by/2.0) which permits unrestricted use, distribution and reproduction in any medium, provided the work is properly cited. treat hepatorenal, cardiovascular, gastrointestinal, and hematological disorders [11], anxiety, asthma, bronchitis, cough, conjunctivitis, arthralgia, psoriasis, and diabetes [12].

There were less evidences regarding efficacy of $M$. oleifera against cadmium-induced toxicity, keeping in mind we conducted this study to evaluate the hepatoprotective activity of $M$. oleifera.

\section{Materials and Methods \\ Ethical approval}

The protocol of the experiment was approved by the Institutional Animal Ethics Committee with approval number 134/IAEC/RVC and protocols were followed according to the guidelines given by Committee for the Purpose of Control and Supervision of Experiments on Animals.

\section{Experimental animals}

A total of 18 Wistar albino rats were taken and randomly divided into three groups $(n=6)$. They are housed in propylene cages under standard laboratory conditions with standard food and water ad-libitum. For this study, control in which healthy rats were given standard feed and deionized water, Group I rats were given cadmium chloride @ 200 ppm per kg daily oral for 28 days and Group II rats. M. oleifera leaf extract@200mg/kg along with cadmium chloride@ $200 \mathrm{ppm}$ per kg orally daily for 28 days. 


\section{Chemicals}

Cadmium chloride was dissolved in distilled water and given orally to individual animal @, 200 ppm [13].

\section{Plant extract}

The leaves of M. oleifera were collected, washed with distilled water, shade-dried, pulverized and freshly prepared powder $(25 \mathrm{~g})$ were immersed in hydro-alcoholic solution ( $40 \%$ distilled water $+60 \%$ ethanol) in a flask stoppered and was kept at room temperature for $48 \mathrm{~h}$ at $150 \mathrm{rpm}$ in orbital shaker. The contents were filtered through muslin cloth and filtered through whatman No. 1 filter paper and extract dried in a Petri dish at room temperature and used along with gum acacia @ 500 mg/kg [14] was given to individual animal with oral gavage needle.

\section{Sample collection}

Blood samples were collected into ethylenediaminetetraacetic acid vials as well as in plain vials on day 29 from the heart puncture. Serum was separated by following standard procedure and was kept in the refrigerator at $4^{\circ} \mathrm{C}$ till analysis. Liver was collected and kept in $-20^{\circ} \mathrm{C}$ for the estimation of oxidative stress parameters and cadmium concentration.

\section{Biochemical estimation}

Aspartate aminotransferase (AST), alanine transaminase (ALT) and alkaline phosphatase (ALP) in serum were analyzed using Erba Semi-auto analyzer by Erba-biochemkits.

\section{Oxidative stress parameters}

The pieces of liver thus collected after the sacrifice of the experimental animals were washed in ice cold saline and $200 \mathrm{mg}$ of liver tissue sample was weighed and taken in $2 \mathrm{ml}$ of ice-cold saline. The homogenate was prepared in Remi-Homogeniser and was centrifuged at $3000 \mathrm{rpm}$ for $10 \mathrm{~min}$. The supernatant was used for the estimation of following oxidative stress indices. Superoxide dismutase was estimated [15]. The extent of lipid peroxidation was evaluated in terms of malondialdehyde production, determined by the thiobarbituric acid method [16].

\section{Cadmium concentration}

Cadmium concentration was quantitatively analyzed on day 29 liver tissue with the help of AAS [17]. The tissue sample was digested using acid and filtrate was prepared by using Millipore water. Then final volume was made up to $10 \mathrm{ml}$ with Millipore water for reading on An Elico double beam atomic absorption spectrophotometer SL 176 model used for total cadmium estimation. Working standards were prepared by dilution of stock $(1000 \mu \mathrm{g} / \mathrm{ml})$ and intermediate $(30 \mu \mathrm{g} / \mathrm{ml})$ standards. The working standards were as follows: $0,0.2,0.5,0.8,1,10,20,30 \mu \mathrm{g} / \mathrm{ml}$ and prepared it by the same procedure as a test.

\section{Statistical analysis}

Quantitative data were analyzed, using the ANOVA. A value $p \leq 0.05$ and $p \leq 0.01$ were considered significant at $5 \%$ and $1 \%$, level respectively.

\section{Results}

\section{Serum bio-markers}

It is evident from Table- 1 that serum biomarker levels of ALT, AST, and ALP were significantly $(p<0.01)$ higher in both Groups II and III compared to Group I, though the activities of enzymes were significantly $(p<0.01)$ lower in Group III compared to Group II.

\section{Oxidative stress indices}

It is transpired from Table- 1 that lipid peroxidation in liver tissue was significantly $(\mathrm{p}<0.01)$ higher in only cadmium treated group (Group II) whereas M. oleifera treated animals (Group III) showed significant $(p<0.05)$ decrease in lipid peroxidation compared to the Group II. Superoxide dismutase (SOD) level in liver was significantly $(\mathrm{p}<0.01)$ lower in both Group I and Group II compared to control group, though the level was again significantly $(\mathrm{p}<0.01)$ higher in Group II compared to Group I (Table-1).

\section{Cadmium concentration}

At the end of the experiment on $29^{\text {th }}$ day, there was significant $(p<0.01)$ increase in cadmium concentration in liver tissue of Group I and Group II as compared to the control group (Table-1). There was no significant difference in cadmium concentration in Group II as compared with Group I.

\section{Discussion}

Cadmium is a non- essential trace element which is toxic to many plants and animals. Large numbers of enzymatic activities are influenced by cadmium and the mechanism of this effect has been hypothesized to be due to their displacement of a beneficial metal from the active site in the enzyme itself [18]. Exposure to cadmium for a short period of time affects the liver [19]. In the present study, there was a significant increase in ALT, ALP, and AST levels were observed (Table 1) indicates liver damage. Elevated serum levels ALT, ALP, and AST may be due to hepatocellular necrosis, which caused increase in the permeability of the cell membrane resulting in the release of transaminases in the blood stream. The increase in alkaline phosphatase activities represent general hepatic toxicity [20]. Induction of alkaline phosphates synthesis is the usual response of the liver to any form of biliary obstruction [21]. Similar finding was observed by [22-28]. There was significant decrease in ALT, ALP, and AST levels when co-treated with cadmium and $M$. oleifera (Table-1). It might be due to hepatoprotective activity. The reversal of elevated serum intracellular enzyme levels by MO extract may be attributed to the stabilizing ability of the cell membrane preventing enzyme leakages as earlier postulated [29] and might be due to hepatoprotective property of $M$. Oleifera leaf extract. Previous study reported hepatoprotective effect was due to presence of Quercetin and kaempferol [30]. In the present study, there was increase in lipid peroxidation and decrease in SOD was observed in rats 
Table-1: Effect of Moringa oleifera against cadmium treated groups on various parameters (mean $\pm S E)(n=6)$.

\begin{tabular}{lccc}
\hline Parameters & Control & Group I & Group II \\
\hline ALT (I.U/L) & $37.75 \pm 0.88$ & $69.72 \pm 0.85^{* *}$ & $51.57 \pm 0.89^{A * *}$ \\
AST (I.U/L) & $187.03 \pm 1.43$ & $224.90 \pm 1.21^{* *}$ & $191.47 \pm 0.86^{A * *}$ \\
ALP (I.U/L) & $113.53 \pm 1.04$ & $152.26 \pm 1.53^{* *}$ & $134.64 \pm 2.03^{A * *}$ \\
LPO (Nm MDA g & -1 ) & $3.44 \pm 0.21^{* *}$ & $2.74 \pm 0.26^{A *}$ \\
SOD (U/mg of protein) & $4.65 \pm 0.21$ & $2.93 \pm 0.18^{* *}$ & $3.69 \pm 0.22^{A * *}$ \\
Liver (ppm) & $0.09 \pm 0.02$ & $19.28 \pm 0.41^{* *}$ & $17.30 \pm 1.49^{\mathrm{NS}}$ \\
\hline
\end{tabular}

${ }^{* *} \mathrm{p}<0.01 ;{ }^{*} \mathrm{p}<0.05$; statistically significant when compared to control group, ${ }^{A *} \mathrm{p}<0.05 ;{ }^{A * *} \mathrm{p}<0.01 ;$ statistically significant when compared to Group I, NS=Statistically non-significant when compared with Group I, LPO=Lipid peroxidation, $\mathrm{AST}=$ Aspartate aminotransferase, $\mathrm{ALT}=$ Alanine transaminase, $\mathrm{ALP}=$ Alkaline phosphatase, $\mathrm{SOD}=\mathrm{Superoxide}$ dismutase, SE=Standard error, M. oleifera=Moringa oleifera

of cadmium chloride treated group (Table-1). It correlates with the studies of [31-34]. This might be due to the peroxidation of membrane lipids and injury to the cellular components.

Reduction in lipid peroxidation and increase in SOD level was observed when cadmium was co-treated with $M$. oleifera (Table-1). It might be due to the presence of flavonoids such as quercetin and kaempferol, vitamin A, ascorbic acid. Ascorbic acid is considered as a potent antioxidant. Similar findings were observed by [35-38]. Significant increase in cadmium level in liver was observed in cadmium treated rats (Group I) and (Group II) as compared to control the group. It is generally known that cadmium is mainly accumulated in kidneys and liver [39] because these organs contain most of metallothionein binding toxic metals [40]. Study proves that exposure to cadmium for 28 days causes toxicity in the body. It was confirmed by the results shown in this study.

\section{Conclusion}

M. oleifera possess antioxidant and free radical scavenging property, which could be helpful in reducing the oxidative stress caused by cadmium, by reducing the ROS production, maintaining the antioxidant potential, and significantly reducing elevated serum biomarker levels in the body. Our study shows that supplementation of M. oleifera extract (@ 500 mg/kg) showed hepatoprotective effect against cadmium toxicity.

\section{Authors' Contributions}

BKR supervised the overall research work. RT, RHG, PK, SLB participated in research work, analysed the samples, statistically analysed the results, modified the article and made available relevant literatures. All authors read and approved the final manuscript.

\section{Acknowledgments}

The authors are thankful and obliged to ICAR for providing fund for conducting this research.

\section{Competing Interests}

The authors declare that they have no competing interests.

\section{References}

1. Patrick, L. (2003) Toxic metals and antioxidants: Part II: The role of antioxidants in arsenic and cadmium toxicity. Altern. Med. Rev., 8(2):106-128.

2. Mehana, E.S. (2008). Pathological and clinico-pathological studies on the protective effect of vitamin E against cadmium chloride toxicosis in male albino rats. Egypt. $J$. Comp. Path. Clin. Path., 21(3): 32-52.

3. Tarasub, N., Devakul, N. and Ayutthaya, W. (2008) Effect of curcumin on cadmium-induced hepatotoxicity in rats. Thai. J. Toxicol., 23(2): 100-107.

4. Ajilore, B.S. and Olugbenga, A. (2012) Hepatoprotective potentials of methanolic extract of the leaf of Momordica charantia linn on cadmium induced hepatotoxicity in rats. J. Nat. Sci. Res., 2(7): 41-47.

5. Amara, S., Douki, T., Garrel, C., Favier, A., Rhouma, K., Sakly, M. and Abdelmelek, H. (2011) Effect of static magnetic field and cadmium on oxidative stress and DNA damage in rat cortex brain and hippocampus. Toxicol. Indian. Health., 27(2): 99-106.

6. Davidson-Hunt, I. (2000) Ecological ethno botany: Stumbling toward new practices and paradigms. MASA J., 16: 1-13.

7. Sinha, M., Das, D.K., Datta, S., Gosh, S. and Dey, S. (2011) Amelioration of ionizing radiation induced lipid peroxidation in mouse liver by Moringa oleifera Lam. Leaf extract. Indian. J. Exp. Biol., 50(3): 209-215.

8. Onyekaba1, T.U., Chinedu, O.G. and Fred, A.C. (2013) Phytochemical screening and investigations of antibacterial activities of various fractions of the ethanol leaves extract of Moringa oleifera LAM (Moringaceae). J. Pharm. Chem. Biol. Sci., 3(3): 962-973.

9. Anwar, F. and Rashid, U. (2007) Physiochemical characteristics of Moringa oleifera seeds and seed oil from a wild provenance of Pakistan. Pak. J. Bot., 39: 1443-1453.

10. Walter, A. (2011) Antibacterial activity of Moringa oleifera and Moringa stenopetala methanol and n-hexane seed extracts on bacteria implicated in water-borne diseases. Afr. J. Microbiol. Res., 51: 153-157.

11. Paliwal, R. (2011) Elucidation of free radical scavenging and antioxidant activity of aqueous and hydro-ethanolic extracts of Moringa oleifera pods. Res. J. Pharm. Tech., 4: 566-571.

12. Nikkon, F. (2003) In vitro antimicrobial activity of the compound isolated from chloroform extract of Moringa oleifera Lam. Pak. J. Biol. Sci., 22: 1888-1890.

13. Gehan, A.E.El-Emery and Ayman, Y.A. (2010) Cadmium ginger two way antagonistic relationship. Arab. J. Biotech., 13(1): 115-124.

14. Kumar, C.S., Balamurugan, B., Merugeswaran, S., Natarajan, P., Haravanan, S.P., Petchimuthu, S and Murungan, T.S. (2010) Protective activity of leaves and roots extracts of Moringa Oleifera Lam. Int. J. Medicobiol. Res., 1(2): 90-93.

15. Madesh, M. and Balasubramanian, K.A. (1998) Microtiter plate assay for superoxide dismutase using MTT reduction by superoxide. Indian. J. Biochem. Biophys., 35(3): 184-188. 
16. Rehman, S.U. (1984) Lead induced regional lipid peroxidation in brain. Toxicol. Lett., 21(3): 333-337.

17. Datta, B.K., Mishra, A., Singh, A., Sar, T.K., Sarkar, S., Bhatacharya, A., Chakraborty, A.K. and Mandal, T.K. (2010) Chronic arsenicosis in cattle with special reference to its metabolism in arsenic endemic village of Nadia district West Bengal India. Sci Total Environ, 409(2): 284-288.

18. Stillman, M.J. and Zelazowski, A.J. (1988) Domain specificity in metal binding to metallothi - Onein. A circular dichroism and magnetic circular dichroism study of cadmium and zinc binding at temperature extremes. J. Biol. Chem., 263(13): 6128-6133.

19. Habeebu, J., Liu, J. and Klaassen, C.D. (1998) Cadmiuminduced apoptosis in mouse liver. Toxicol. Appl. Pharmacol., 149: 203-209.

20. Naik, P. (2010) Biochemistry. $3^{\text {rd }}$ ed. Jaypee Publishers Ltd, Panama. p138-141, 565.

21. Mauro, P. and Renze, B. (2008) In: Fundamentals of Clinical Chemistry. $6^{\text {th }}$ ed. p325.

22. Haidry, M.T. and Malik. A. (2014) Hepatoprotective and antioxidative effects of Terminalia arjuna against cadmium provoked toxicity in Albino rats (Ratus norvigieus). Biochem. Pharmacol., 3: 1.

23. Ibiam, A.U., Ugwuja, E.I., Ejeogo, C. and Ugwu, O. (2013) Cadmium induced toxicity and the hepatoprotective potentials of aqueous extract of Jessiaca nervosa leaf. $A d v$. Pharm Bulletin., 3(2): 309-313.

24. Rajasekaran, A. and Periasamy, M. (2012) Hepatoprotective effect of ethanolic leaf extract of Calycopteris floribunda lam on cadmium induced hepatotoxicity in rats. Res. $J$. Pharm. Biol. Chem. Sci., 3(3): 382-390.

25. Gaurav, D., Preet, S. and Dua, K.K. (2011) Protective influence of dietary nutrients on antioxidant defense system in the blood of rats treated with cadmium. Adv. Appl. Sci. Res., 2(2): 69-78.

26. Uchida, H., Kurata, Y., Hiratsuka, H. and Umemura, T. (2010) The effect of vitamin D deficient diet on chronic cadmium exposure in rats. Toxicol. Pathol., 38(5): 730-737.

27. Kumar, P.V., Pricy, A.A., Kumar, C.S. and Goud, G.K.K. (2010) Hepatoprotective effect of green tea (Camellia sinesis) on cadmium chloride induced toxicity in rats. J. Chem. Pharm. Res., 2(6): 125-128.

28. Ibrahim, N.K. (2013) Possible protective effect of kombucha tea ferment on cadmium chloride induced liver and kidney damage in irradiated rats Int. J. Biol. Life Sci., 9:1.

29. Pari, L. and Karthikesan, K. (2007) Protective role of caffeic acid against alcohol - Induced biochemical changes in rats. Fundam Clin Pharmacol., 21(4): 355-361.

30. Selvakumar, D. and Natarajan, P. (2008) Hepatoprotective activity of Moringa oleifera Lam. leaves in carbon tetrachloride induced hepatotoxicity in albino rats. Pharmacogn. Mag., 4: 97-98.

31. Mitra, E., Ghosh, A.K., Ghosh, D., Firdaus, S.Y., Mukherjee, D., Chattopadhya, A., Pattari, S.K., Dutta, S. and Bandyopadhya, D.(2013) Ameliorative effect of aqueous curry leaf (Murraya Koenigi) extract against cadmium induced oxidative stress in rat liver: Involvement of antioxidant mechanisms. Int. J. Pharm. Pharm. Sci., 5(2): 570-583.

32. Esther, A.O., Funnmilola, O.Y., Violette, A.N. and Oziegbe, O.O. (2013) Effect of African Walnut (Tetracarpidium conophorum (Mull. Arg.). Hutch and Dalziel syn. PlukenetI conophora oil on cadmium - Induced oxidative stress in male albino rats. Res. J. Pharm. Biol. Chem. Sci., 4(3): 35-42.

33. Ognjanovic, B.I., Markovic, S.D., Pavlovic, S.Z., Zikic, R.V., Stajn, A.S. and Saicic, Z.S. (2007) Effect of chronic cadmium exposure on antioxidant defence system in some tissue of rats: Protective effect of selenium. Pysiol. Res., 57: 403-411.

34. Aslam, M., Ahmad, S.T., Dayal, R., Javid, K., Umar, S., Asiaf, A., Nafees, S., Bhat, J.A., Wani, A., Samim, M. and Singh, S. (2012) Nephroprotective action of Peucedanum grande against cadmium chloride induced renal toxicity in wistar rats. EXCLI J., 11: 444-452.

35. Bharali, R., Tabassum, J. and Azad, M.R.H. (2003) Chemomodulatory effect of Moringa oleifera, Lam. on hepatic carcinogen metabolizing enzymes, antioxidant parameters and skin papillomagenesis in mice. Asian. Pac. J. Cancer. Prev., 4: 131-139.

36. Kumar, N.A. and Pari, L. (2003) Antioxidant action of Moringa oleifera Lam. (Drumstick) against antitubercular drugs induced lipid peroxidation in rats. J. Med. Peroxid. Food., 6(3): 255-259.

37. Sultana, B., Anwar, F. and Ashraf, M. (2009) Effect of extraction solvent/technique on the antioxidant activity of selected medicinal plant extracts. Molecules., 14: 167-2180.

38. Sreelatha, S. and Padma, P.R. (2009) Antioxidant activity and total phenolic content of Moringa oleifera leav.es in two stages of maturity. Plant Foods Human. Nutr., 64: 303-311.

39. Massanyi, P., Tataruch, F., Slamecka, J., Toman, R. and Jurcik, R. (2003) Accumulation of lead, cadmium, and mercury in liver and kidney of the brown hare (Lepus europaeus) in relation to the season, age, and sex in the West Slovakian Lowland. J. Environ. Sci. Health., 39: 1299-1309.

40. Hollis, L., Hogstrand, C. and Wood, C.M. (2001) Tissuespecific cadmium accumulation, metallothionein induction, and tissue zinc and copper levels during chronic sublethal cadmium exposure in juvenile rainbow trout. Arch. Environ. Contam. Toxicol., 41: 468-474. 